\title{
AVALIAÇÃO DA DRENAGEM DE LODOS DE DECANTADORES DE ETAS EM SISTEMAS DE DESAGUAMENTO COM MANTA GEOTÊXTIL
}

\section{Cristiane Silveira Leonardo Yoshiaki Abe Marcos Batista Mendes}

RESUMO: O tratamento de lodos de decantadores de Estações de Tratamento de Água ETAs, através do desaguamento por leito de drenagem / secagem com manta geotêxtil tem apresentado resultados promissores para aplicação no Brasil. O objetivo deste estudo foi avaliar o sistema de desaguamento de dois lodos de decantadores de ETAs em protótipos de escala reduzida, através do monitoramento da fase de drenagem considerando as características do manancial e produtos químicos aplicados no tratamento de água, e aspectos técnicos de projeto como a densidade da manta, taxa de aplicação de sólidos - TAS, taxa de aplicação volumétrica - TAV. Os resultados obtidos mostraram que os líquidos que percolaram através do leito de drenagem apresentaram qualidade compatível com corpos de água doce classe I e II segundo Resolução 357/05 do Conama, bem como com a recirculação para produção de água na ETA.

Palavras-chaves: Lodo de decantador. Desaguamento. Manta geotêxtil.

\section{INTRODUÇÃO}

Os lodos de decantadores de estações de tratamento de águas - ETAs, são basicamente o produto da coagulação da água bruta e, assim tem uma composição aproximada daquela, acrescidos dos produtos resultantes do coagulante utilizado, principalmente hidróxidos de alumínio e de ferro. Caracterizam-se por possuir grande teor 
de umidade, geralmente maior que 95\%, sendo classificados pela NBR 10.004 / 04 como resíduos sólidos.

Em função dos inúmeros impactos que podem causar, dentre eles a redução da qualidade de água pela adição de sólidos e microrganismos removidos previamente no tratamento de água, alterações da biota aquática, redução do volume útil do rio devido ao assoreamento e possíveis efeitos tóxicos aos seres humanos e animais, seu lançamento in natura no meio ambiente não é permitido.

O tratamento de lodos de ETAs consiste basicamente numa separação sólidolíquido, via clarificação / adensamento e desidratação e tem como objetivo a redução de volume do lodo, obtenção de maior teor de sólidos, possibilitando a disposição adequada da fração sólida, seja em aterros sanitários em substituição ao solo utilizado, codisposição com matrizes de cimento, concreto, entre outros. O desaguamento possibilita ainda que a água removida seja reaproveitada no processo de tratamento de águas ou descartada no corpo de água sem causar grandes prejuízos (ACHON, 2003).

A redução do volume de água pode ser realizada através da remoção da água livre e nos interstícios dos sólidos por sistemas naturais ou mecânicos. O tipo de sistema a ser adotado depende de vários fatores, como: área necessária para a implantação do sistema de desaguamento, custo de equipamentos, operação e transporte, condições climáticas, entre outros.

O desaguamento do lodo pode ser realizado de forma mecânica por equipamentos que possuem custos elevados de aquisição, requerem a aplicação de produtos químicos e consomem energia elétrica para seu funcionamento como filtros a vácuo, filtros prensas de placas / esteira e centrífugas, ou natural, por meio de lagoas de lodo e leitos de drenagem / secagem.

Estudos realizados por Cordeiro (1993; 2000; 2001), Achon (2003), Fontana (2004) e Barroso (2007), mostraram que o Brasil apresenta condições favoráveis para a utilização do desaguamento natural em leitos de drenagem / secagem com uso de mantas geotêxteis. No entanto, há ainda algumas questões não esclarecidas, especialmente em relação aos critérios de dimensionamento, tais como parâmetros físicos e operacionais de 
projeto, considerando a qualidade da água bruta, produtos químicos aplicados no tratamento.

O objetivo geral deste estudo foi avaliar o desempenho do sistema de desaguamento de dois lodos de decantadores de ETAs em leito de drenagem / secagem com uso de manta geotêxtil em protótipos de escala reduzida, através do monitoramento da fase de drenagem, considerando os seguintes aspectos:

- Características do manancial e produtos químicos aplicados no tratamento de água;

- Remoção dos contaminantes presentes no lodo, dentre eles metais pesados, matéria orgânica (DBO, DQO), cor, turbidez e sólidos;

- Densidade da manta, taxa de aplicação de sólidos - TAS e taxa de aplicação volumétrica - TAV.

\section{MATERIAIS E MÉTODOS}

\section{$2.1 \quad$ Lodos de estudo}

Foram utilizados os lodos de decantadores tipo A, proveniente da ETA Cafezal e utiliza o cloreto férrico como coagulante químico, e tipo $\mathrm{B}$, proveniente da ETA Tibagi, que utiliza o hidróxi-cloreto de polialumínio como coagulante químico, ambas localizadas na cidade de Londrina - PR.

\subsection{Ensaios de desaguamento}

As unidades de desaguamento em escala reduzida foram compostas por um tanque de polietileno com capacidade de $320 \mathrm{~L}$, provido de uma grelha plástica para suporte da manta geotêxtil e tubulação de saída inferior para coleta da água drenada, como mostra a Figura 1. 


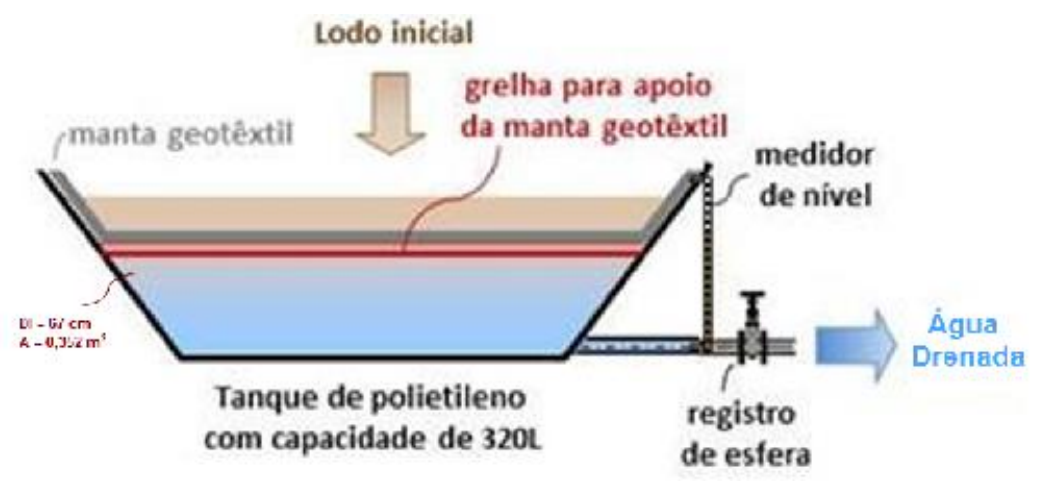

Figura 1 - Esquema da unidade de desaguamento

Na Tabela 1 são apresentados os parâmetros de projeto aplicados nos ensaios, os quais são resultantes do cálculo realizado em função dos teores de sólidos totais - ST dos lodos e taxa de aplicação de sólidos - TAS pré-estabelecida.

Tabela 1 - Parâmetros de projeto aplicados nos ensaios de desaguamento

\begin{tabular}{|l|c|c|c|c|c|c|c|}
\hline & $\begin{array}{c}\text { Gramatura } \\
\text { da manta } \\
\left(\mathrm{g} \cdot \mathrm{m}^{-2}\right.\end{array}$ & $\begin{array}{c}\text { Densidade } \\
\text { da manta } \\
\left(\mathrm{g} \cdot \mathrm{m}^{-2}\right)\end{array}$ & $\begin{array}{c}\text { Teor de } \\
\text { ST (\%) }\end{array}$ & $\begin{array}{c}\text { Taxa de } \\
\text { aplicação de } \\
\text { sólidos }- \\
\text { TAS }\left(\mathrm{kg} \cdot \mathrm{m}^{-2}\right)\end{array}$ & $\begin{array}{c}\text { Taxa de aplicação } \\
\text { volumétrica - TAV } \\
\left(\mathrm{m}^{3} \cdot \mathrm{m}^{-2} \cdot \mathrm{d}^{-1}\right)\end{array}$ & $\begin{array}{c}\text { Volume de } \\
\text { lodo } \\
\text { aplicado } \\
(\mathrm{L})\end{array}$ & $\begin{array}{c}\text { Vazão de } \\
\text { aplicação } \\
\left(\mathrm{mL}^{\left.-\mathrm{min}^{-1}\right)}\right.\end{array}$ \\
\hline Lodo tipo A & 600 & 600 & 0,91 & 7,5 & 20 & 293,8 & 5.000 \\
\hline Lodo tipo B & 600 & 600 & 1,27 & 6,5 & 14 & 164,5 & 3.500 \\
\hline
\end{tabular}

Para avaliar o desempenho da drenagem, toda a água drenada foi coletada em frascos de volume pré-estabelecido e acondicionados sob refrigeração para posterior análise.

Considerando o lançamento direto da totalidade do volume drenado, foi constituída uma amostra composta dos lodos drenados - ACD IV, utilizando-se volumes fixos de todas as amostras coletadas ao longo do tempo.

Complementarmente, para sistematizar os resultados em relação à qualidade de água drenada, foram estabelecidas 2 condições de enquadramento (I e II) e 1 condição de reaproveitamento (III): 
- Condição I: líquidos percolados com valores de turbidez inferiores à 40 UT considerando a possibilidade de lançamento da água drenada em corpos de água doce Classe I, segundo estabelecido pela Resolução 357/05 do Conama;

- Condição II: líquidos percolados com valores de turbidez inferiores à 100 UT considerando a possibilidade de lançamento da água drenada em corpos de água doce Classe II, segundo estabelecido pela Resolução 357/05 do Conama, classificação da maioria dos corpos hídricos receptores da região;

- Condição III: líquidos percolados com valores de turbidez inferiores à 10 UT considerando a possibilidade de reaproveitamento da água drenada no sistema de produção de água da própria ETA.

Assim, foram constituídas amostras compostas dos líquidos percolados considerando cada condição (ACD I, II e III), isto é, utilizando-se volumes fixos de todas as amostras coletadas com valores de turbidez inferiores à 40; 100 e 10 uT, respectivamente.

Os lodos iniciais tipos $\mathrm{A}$ e $\mathrm{B}$ e as amostras compostas dos líquidos percolados foram caracterizados quanto aos parâmetros físicos, químicos e microbiológicos seguindo procedimentos da APHA, AWWA e WEF (2005) com adaptações, apresentados na Tabela 2. 
Tabela 2 - Parâmetros e métodos / equipamentos utilizados na caracterização dos lodos e líquidos percolados

\begin{tabular}{|c|c|}
\hline Parâmetro & Método \\
\hline Turbidez (uT) & Nefelométrico - $2130 \mathrm{~B}$ \\
\hline Cor aparente $(\mathrm{uH})$ & Espectrofotométrico- $2120 \mathrm{C}$ \\
\hline Cor verdadeira $(\mathrm{uH})$ & $\begin{array}{c}\text { Espectrofotométrico - } 2120 \text { C Filtrado em membrana } \\
\text { tipo GF/C }\end{array}$ \\
\hline $\begin{array}{l}\text { Demanda Bioquímica de Oxigênio - } \mathrm{DBO}_{5 \mathrm{~d}}, 20^{\circ} \mathrm{C} \\
\qquad\left(\mathrm{mg} \cdot \mathrm{L}^{-1}\right)\end{array}$ & Teste DBO 5 dias a $20^{\circ} \mathrm{C}-5210$ \\
\hline Demanda Química de Oxigênio DQO $\left(\mathrm{mg}^{-\mathrm{L}^{-1}}\right)$ & Refluxo fechado - $5220 \mathrm{D}$ \\
\hline Série de sólidos $\left(\mathrm{mg} \mathrm{L}^{-1}\right)$ & $\begin{array}{l}\text { Sólidos secos a } 103-105^{\circ} \mathrm{C} \text {; Sólidos voláteis } \\
\text { incinerados a } 550^{\circ} \mathrm{C}-2540\end{array}$ \\
\hline Coliformes totais e E. coli (NMP/100mL) & Substrato cromogênico / colilert - 9223 \\
\hline $\begin{array}{l}\text { Alúminio, Cálcio, Chumbo, Cobalto, Cobre, Cromo, } \\
\text { Ferro, Fósforo, Magnésio, Manganês, Níquel, } \\
\text { Potássio, Silício, Sódio, Titânio, Zinco Totais }\left(\mathrm{mg}^{-1} \mathrm{~L}^{-1}\right)\end{array}$ & ICP-OES Plasma/ 3125 \\
\hline
\end{tabular}

\section{RESULTADOS}

\subsection{Ensaios de desaguamento}

As Figuras 2 e 3 mostram os resultados obtidos na fase de drenagem dos lodos tipos $A$ e $B$, respectivamente. 


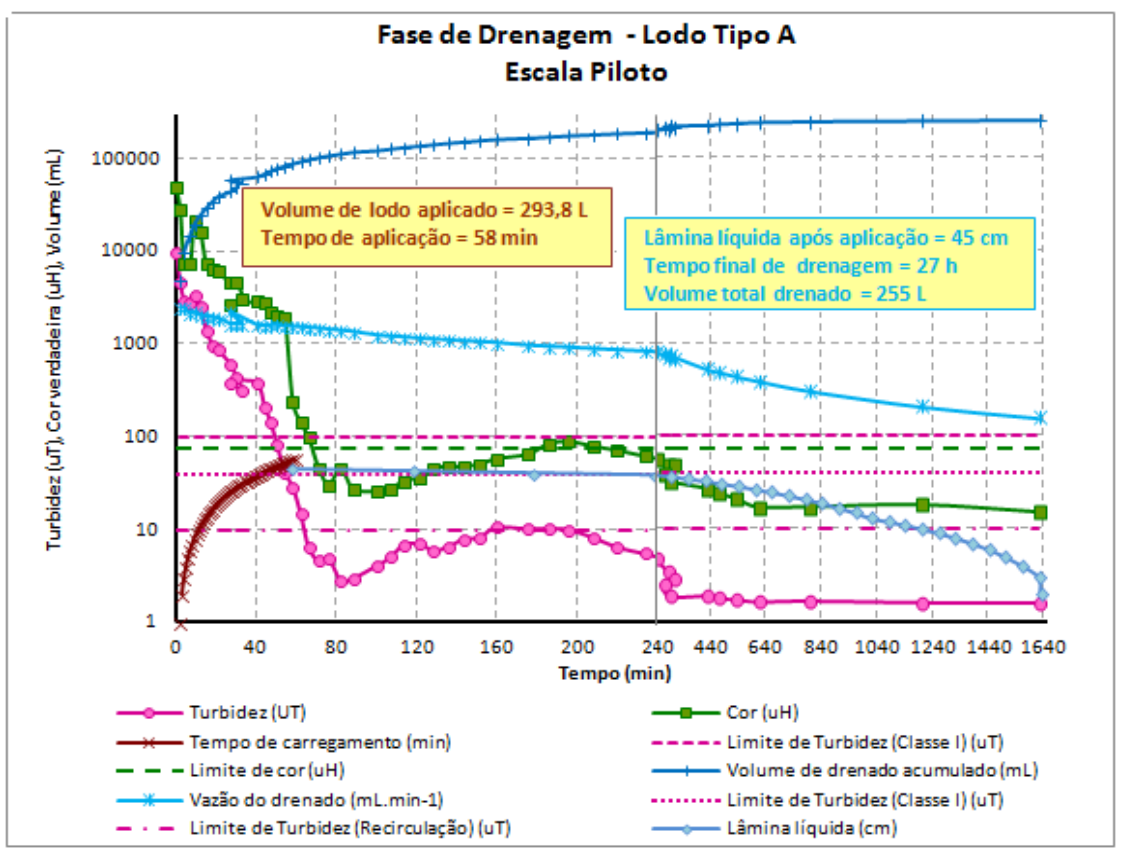

Figura 2 - Resultados da fase de drenagem para o tipo A

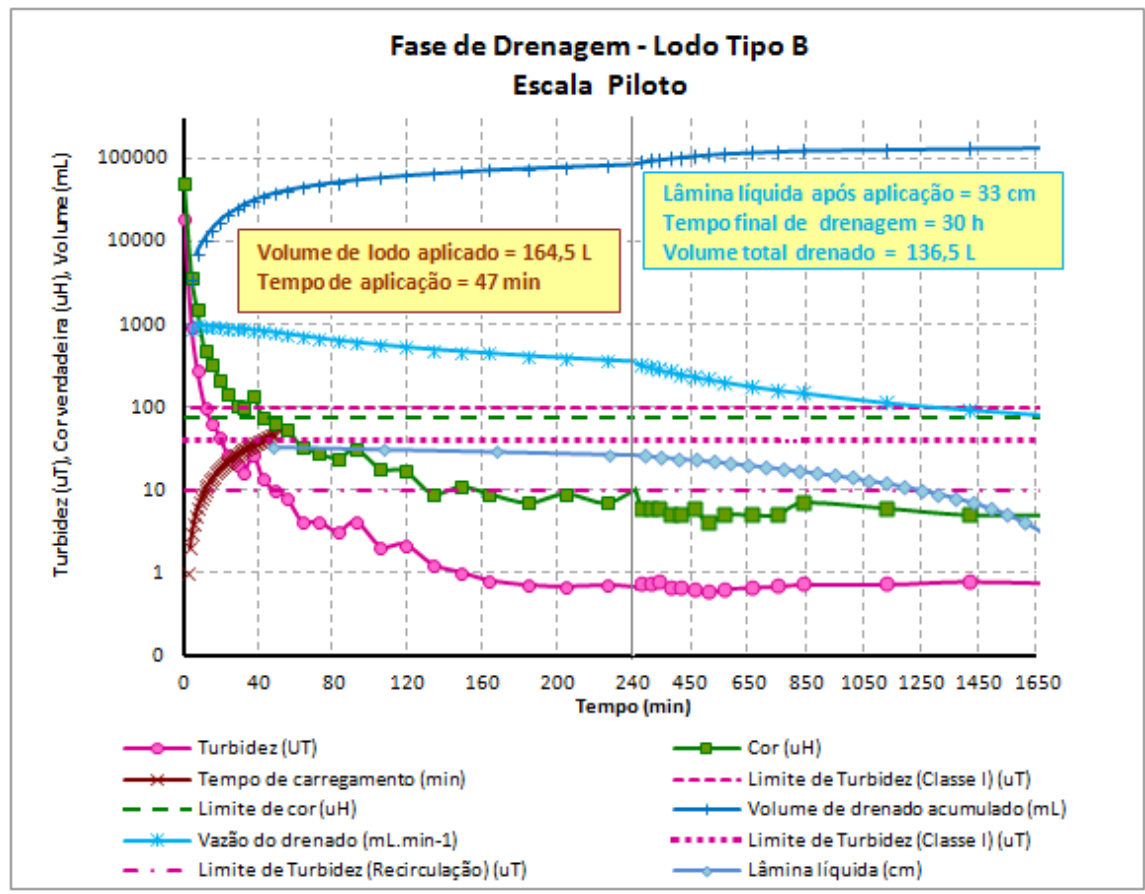

Figura 3 - Resultados da fase de drenagem para o tipo B

A Tabela 3 mostra algumas diferenças observadas entre as fases de drenagem dos lodos tipos A e B. 
Tabela 3 - Observações da fase de drenagem dos lodos tipos A e B

\begin{tabular}{|c|c|c|}
\hline & Lodo tipo A & Lodo tipo B \\
\hline Tempo requerido para extinção da lâmina líquida (h) & 27 & 30 \\
\hline Redução do volume total de lodo aplicado (\%) & 86 & 83 \\
\hline $\begin{array}{c}\text { Tempo requerido para produção de líquidos percolados com turbidez } \leq 100 \\
\text { uT (min) }\end{array}$ & 50 & 15 \\
\hline $\begin{array}{c}\text { Tempo requerido para produção de líquidos percolados com turbidez } \leq 40 \\
\text { uT (min) }\end{array}$ & 58 & 23 \\
\hline $\begin{array}{c}\text { Tempo requerido para produção de líquidos percolados com turbidez } \leq 10 \\
\text { uT (min) }\end{array}$ & 66 & 48 \\
\hline Valor de turbidez do líquido percolado ao final do desaguamento (uT) & 1,5 & 0,75 \\
\hline
\end{tabular}

A diferença no tempo requerido para extinção da lâmina líquida entre os lodos pode ser justificada pelos resultados obtidos no teste de resistência específica, uma vez que o lodo tipo $A$ apresentou resistência específica de $0,035 \times 10^{12} \mathrm{~m} \cdot \mathrm{Kg}^{-1}$, enquanto o lodo tipo B apresentou resistência específica de $4,789 \times 10^{12} \mathrm{~m} \cdot \mathrm{Kg}^{-1}$, indicando que o lodo tipo A apresenta maior facilidade de filtração quando comparado ao lodo tipo B.

Notou-se que para o lodo tipo $\mathrm{B}$, a qualidade do líquido percolado é melhorada logo no início das coletas e consequentemente, as porcentagens de volume de drenado que atenderam às condições de enquadramento I e II e de reaproveitamento III para o lodo tipo $\mathrm{B}$ foram da ordem de $71-89 \%$, superiores às obtidas para o lodo tipo $A$, que resultaram entre $62-69 \%$. As Figuras 4 e 5 mostram as fotos dos líquidos percolados tipos A e B, dispostos por ordem de coleta durante a drenagem.

Figura 4 - Líquidos percolados tipo A

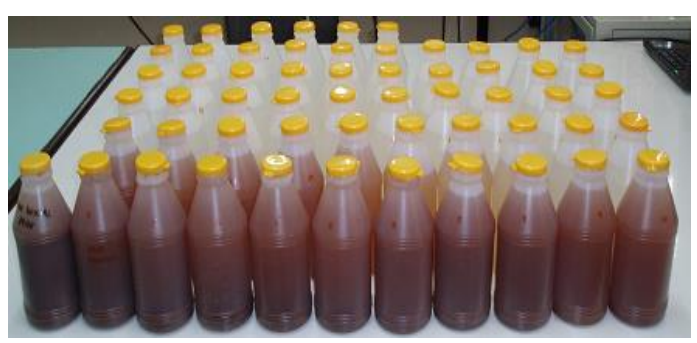

Figura 5- Líquidos percolados tipo B

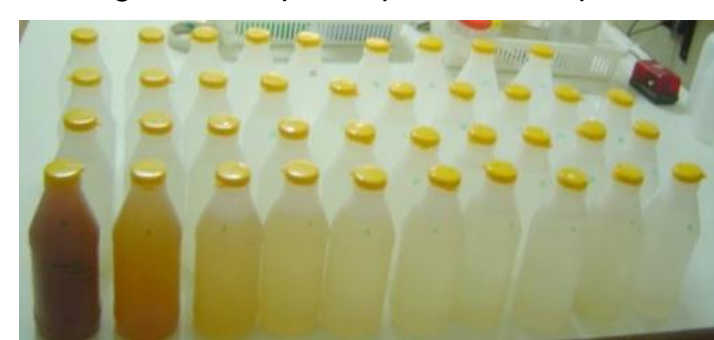


3.2 Caracterização dos lodos iniciais e das amostras compostas dos líquidos percolados

As Figuras 6 e 7 mostram os resultados da caracterização dos lodos inicias e das amostras dos líquidos percolados tipos A e B, respectivamente.

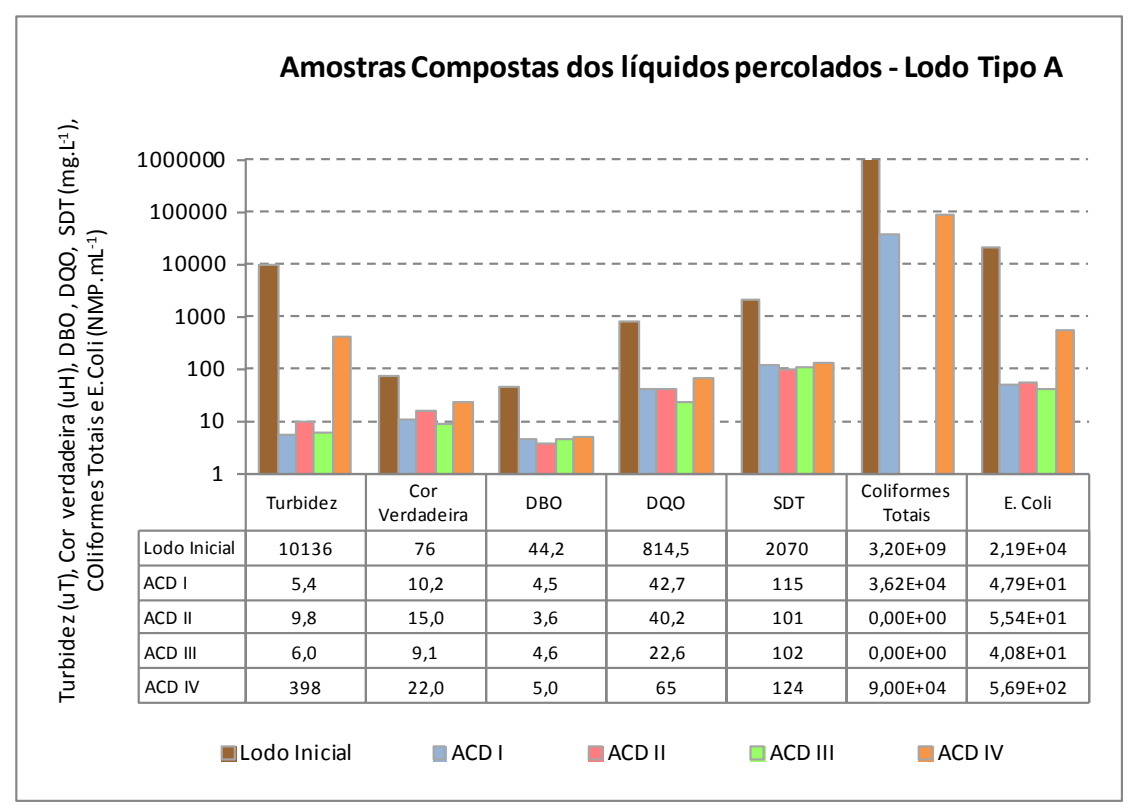

Figura 6 - Resultados da caracterização do lodo inicial tipo A e amostras compostas 


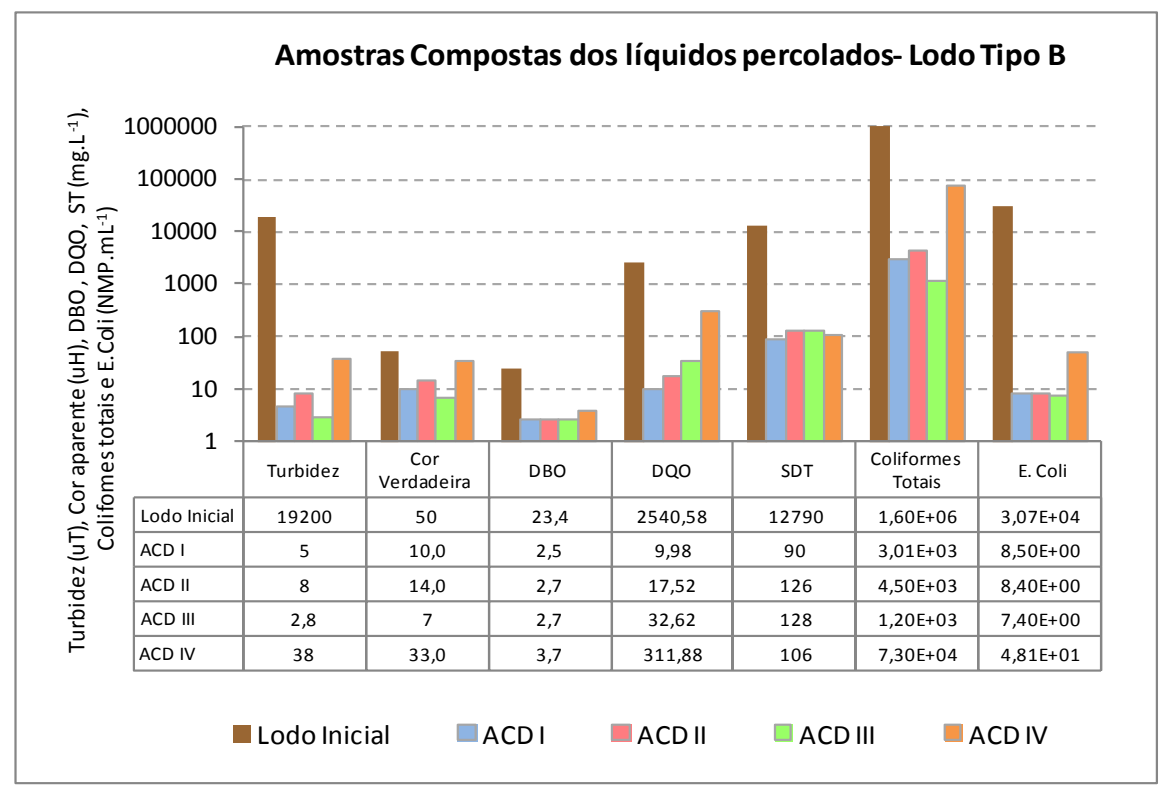

Figura 7 - Resultados da caracterização do lodo inicial tipo B e amostras compostas

Comparando-se os resultados obtidos na caracterização das amostras compostas dos líquidos percolados com os limites estabelecidos pela Resolução 357 /2005 do Conama, pode-se observar que com exceção da ACD IV, as amostras compostas dos líquidos percolados (ACD I e II) dos lodos tipos $A$ e $B$ apresentaram valores compatíveis com os limites máximos permitidos em corpos de água doce classes I e II.

As Tabelas 5 e 6 mostram os valores dos metais analisados nos lodos iniciais e nas amostras compostas dos líquidos percolados para cada condição estabelecida, bem como os limites estabelecidos pela Resolução 357/05 do Conama para enquadramento em corpos de água doce Classe I e II. 
Tabela 5 - Resultados da quantificação de metais no lodo inicial tipo A e nas amostras compostas dos líquidos percolados e limites estabelecidos pela Resolução 357/05 do Conama

\begin{tabular}{|c|c|c|c|c|c|c|c|c|}
\hline $\begin{array}{l}\text { Parâmetro } \\
\text { (Fração total } \\
\text { em mg. } \text { L }^{-1} \text { ) }\end{array}$ & $\begin{array}{c}\text { Lodo Inicial } \\
\text { (Fração } \\
\text { total) }\end{array}$ & $\begin{array}{c}\text { Lodo Inicial } \\
\text { (Fração } \\
\text { dissolvida) }\end{array}$ & ACD I & $A C D \|$ & ACD III & ACD IV & $\begin{array}{l}\text { Limite - } \\
\text { Classe I }\end{array}$ & $\begin{array}{l}\text { Limite - } \\
\text { Classe II }\end{array}$ \\
\hline Alúminio & 237,6 & 0,05 & 0,32 & 0,26 & 0,18 & 11,29 & $0,1^{*}$ & $0,1^{*}$ \\
\hline Ferro & 545,6 & N.D & 1,78 & 0,85 & 0,36 & 50,20 & 0,001 & 0,001 \\
\hline Cálcio & 23,18 & 10,65 & 7,08 & 7,64 & 6,75 & 8,19 & 0,01 & 0,01 \\
\hline Chumbo & 0,41 & N.D & N.D & N.D & N.D & N.D & 0,05 & 0,05 \\
\hline Cobalto & 0,22 & N.D & N.D & N.D & N.D & N.D & 0,009 * & 0,009 * \\
\hline Cobre & 1,29 & 0,031 & 0,05 & 0,046 & 0,046 & 0,10 & 0,05 & 0,05 \\
\hline Cromo & 0,34 & N.D & N.D & N.D & N.D & 0,01 & $0,3^{*}$ & $0,3^{*}$ \\
\hline Fósforo & 0,66 & N.D & 0,05 & $<L . Q$ & $<L . Q$ & $<L . Q$ & 0,02 & 0,03 \\
\hline Magnésio & 7,12 & 3,29 & 2,12 & 2,28 & 2,01 & 2,52 & -- & -- \\
\hline Manganês & 13,71 & N.D & 1,43 & 1,55 & 1,34 & 2,09 & 0,1 & 0,1 \\
\hline Níquel & 0,094 & N.D & N.D & N.D & N.D & N.D & 0,025 & 0,025 \\
\hline Potássio & 1,0 & 0,70 & $<L . Q$ & $<L . Q$ & $<L . Q$ & $<L . Q$ & -- & -- \\
\hline Silício & 58,15 & 6,97 & 4,72 & 4,73 & 4,13 & 17,93 & -- & -- \\
\hline Sódio & 4,3 & 2,10 & 1,50 & 1,50 & 1,40 & 1,90 & -- & -- \\
\hline Titânio & 14,88 & 0,003 & $<L . Q$ & N.D & N.D & 0,77 & -- & -- \\
\hline Zinco & 0,42 & N.D & N.D & N.D & N.D & N.D & 0,18 & 0,18 \\
\hline
\end{tabular}

$\left(^{*}\right)$ Limite referente a concentração de metal na fração dissolvida

Fração dissolvida - lodo filtrado em membrana de fibra de vidro de $0,45 \mu \mathrm{m}$ $<$ L.Q - Abaixo do limite de quantificação

N.D - Não detectado

N.A - Não analisado 
Tabela 6 - Resultados da quantificação de metais no lodo inicial tipo B e nas amostras compostas dos líquidos percolados e limites estabelecidos pela Resolução 357/05 do Conama

\begin{tabular}{|c|c|c|c|c|c|c|c|c|}
\hline $\begin{array}{c}\text { Parâmetro } \\
\text { (Fração } \\
\text { total em } \\
\mathrm{mg} \cdot \mathrm{L}^{-1} \text { ) }\end{array}$ & $\begin{array}{l}\text { Lodo Inicial } \\
\text { (Fração } \\
\text { total) }\end{array}$ & $\begin{array}{l}\text { Lodo Inicial } \\
\text { (Fração } \\
\text { dissolvida) }\end{array}$ & ACD I & $A C D \|$ & ACD III & ACD IV & $\begin{array}{l}\text { Limite - } \\
\text { Classe I }\end{array}$ & $\begin{array}{l}\text { Limite - } \\
\text { Classe II }\end{array}$ \\
\hline Alúminio & 757,7 & 0,077 & 0,17 & 0,35 & 0,24 & 1,28 & $0,1^{*}$ & $0,1^{*}$ \\
\hline Ferro & 324,3 & N.D & $<L . Q$ & 0,60 & 0,10 & 2,72 & 0,001 & 0,001 \\
\hline Cálcio & 16,30 & N.D & 5,20 & 5,88 & 5,66 & 6,34 & 0,01 & 0,01 \\
\hline Chumbo & $<$ L.Q & 10,88 & N.D & N.D & N.D & N.D & 0,05 & 0,05 \\
\hline Cobalto & 0,10 & N.D & N.D & N.D & N.D & N.D & $0,009^{*}$ & 0,009 * \\
\hline Cobre & 0,60 & N.D & 0,045 & 0,046 & 0,046 & 0,043 & 0,05 & 0,05 \\
\hline Cromo & 0,24 & 0,031 & N.D & N.D & N.D & N.D & $0,3^{*}$ & $0,3^{*}$ \\
\hline Fósforo & 8,69 & N.D & N.D & $<L . Q$ & 0,093 & 0,06 & 0,02 & 0,03 \\
\hline Magnésio & 17,20 & 2,46 & 1,51 & 1,75 & 1,69 & 1,88 & -- & -- \\
\hline Manganês & 7,72 & N.D & 0,93 & 1,08 & 1,05 & 1,17 & 0,1 & 0,1 \\
\hline Níquel & 0,10 & N.D & N.D & N.D & N.D & N.D & 0,025 & 0,025 \\
\hline Potássio & 9,60 & 2,40 & 1,0 & $<L . Q$ & 1,0 & 1,10 & -- & -- \\
\hline Silício & 7,54 & 1,99 & 2,28 & 2,94 & 2,42 & 4,04 & -- & -- \\
\hline Sódio & 4,20 & 4,90 & 2,70 & 2,90 & 3,0 & 3,20 & -- & -- \\
\hline Titânio & 5,39 & N.D & N.D & N.D & N.D & 0,04 & -- & -- \\
\hline Zinco & 0,55 & N.D & N.D & N.D & N.D & N.D & 0,18 & 0,18 \\
\hline
\end{tabular}

$\left(^{\star}\right)$ Limite referente a concentração de metal na fração dissolvida

Fração dissolvida - lodo filtrado em membrana de fibra de vidro de $0,45 \mu \mathrm{m}$

$<$ L.Q - Abaixo do limite de quantificação

N.D - Não detectado

N.A - Não analisado

Como pôde-se observar, dentre os metais analisados nos lodos iniciais, o ferro e o alumínio apresentaram-se em maiores concentrações, devido principalmente, aos tipos de coagulante químico empregados nas ETAs.

Em relação à eficiência de remoção de metais, pode-se observar que no desaguamento do lodo tipo $\mathrm{A}$, a redução mínina da concentração de ferro total foi de 90,8\% na amostra composta referente à condição IV e máxima de 99,9\% na amostra 
composta referente à condição III. No desaguamento do lodo tipo $\mathrm{B}$, a redução mínina da concentração de alumínio total foi de $99,8 \%$ na amostra composta referente à condição IV e máxima de 99,9\% na amostra composta referente a condição I. Esses dados comprovam que o uso do sistema de desaguamento é capaz de reduzir substancialmente os prejuízos à qualidade do corpo receptor em relação a esse parâmetro.

Como em relação à fração dissolvida dos metais nos lodos tipos $\mathrm{A}$ e $\mathrm{B}$, apenas 0 cobre apresentou valores superiores ao limite estabelecido pela Resolução 357/05 do Conama para enquadramento em corpos de água Classes I e II, o mesmo pode ocorrer para as amostras compostas dos drenados, especialmente para a ACD IV.

\section{CONCLUSÕES}

Os resultados da caracterização qualitativa nas fases de drenagem para os lodos de estudo mostraram algumas particularidades, especialmente em relação à(s) elevadas concentrações de ferro e alumínio, devido ao emprego de diferentes coagulantes químicos nos lodos tipos $A$ e $B$, predominância de metais na fração particulada e contagens variadas de coliformes totais e de E. Coli, pela adoção da etapa de précloração da água bruta da ETA associada ao lodo tipo A.

$O$ estudo mostrou que tratamento natural de lodos de decantadores de ETAs em leitos de drenagem com manta geotêxtil é eficiente para remoção dos contaminantes presentes no lodo, mesmo sem o uso de produtos químicos. Sendo possível obter uma remoção de mínima de em média $90 \%$ dos metais presentes, além de outras substâncias como matéria orgânica (DBO, DQO), cor, turbidez e sólidos.

De modo geral, nas condições de estudo, independente do tipo de lodo (tipo A ou B), o sistema de desaguamento de lodos de decantadores de ETAs composto por leitos de drenagem / secagem com uso de manta geotêxtil apresentou resultados promissores quanto aos aspectos quali / quantitativos de eficiência na fase de drenagem por possibilitar a produção de líquidos percolados com qualidade compatível para enquadramento em relação à classificação de corpos de água doce (classes I e II) estabelecidos pela Resolução 357/05 do Conama, visando à proteção dos corpos hídricos 
receptores ou ainda pela possibilidade de reaproveitamento da água drenada para produção de água tratada na própria ETA.

\section{REFERÊNCIAS}

ACHON, C. L., CORDEIRO, J. S. Análise crítica de implantação de sistemas naturais de remoção de água livre de lodo de ETA. $22^{\circ}$ Congresso Brasileiro de Engenharia Sanitária e Ambiental, Joinvile, Santa Catarina, 2003.

APHA, AWWA, WEF, Standard Methods For The Examination Of Water \& Wastewater 21st Edition, 2005.

BARROSO, M. M. Influência das micro e macropropriedades dos lodos de Estações de Tratamento de Águas nos Desaguamento por Leito de Drenagem. Tese de Doutorado, Universidade de São Paulo, 2007

CONAMA nํ 357. Resolução CONAMA 357, de 17 de março de 2005. Dispõe sobre a Classificação das Águas Doces, Salobras e Salinas do Território Nacional. Brasília, 2005.

CORDEIRO.J.S. O probelma dos lodos gerados em decantadores de estações de tratamento de água. Tese de Doutorado em Hidráulica e Saneamento- Escola de Engenharia de São Carlos, Universidade de São Paulo, 1993.

CORDEIRO, J. S. Importância do tratamento e disposição adequada de lodos de ETAs (Capítulo I). Coordenador: Reali, M. A. P. Noções gerais de tratamento e disposição de lodos de estações de tratamento de água. Rio de Janeiro: ABES, 1999.

CORDEIRO, J.S. Processamento de lodos de Estações de Tratamento de Água (ETAs). (Capítulo V). Coordenador: ANDREOLI, C.V. Resíduos sólidos do saneamento: Processamento, reciclagem e disposição final. Rio de Janeiro: ABES. Projeto PROSAB 2, 2001. 
FONTANA, A. O. Sistema de Leito de Drenagem e Sedimentador como solução para redução de volume de decantadores e reuso de água de lavagem de filtros - Estudo de Caso - ETA Cardoso. Dissertação de Mestrado, Universidade Federal de São Carlos, 2004. 